\title{
Theoretical study of convergent ultrasound hyperthermia for treating bone tumors
}

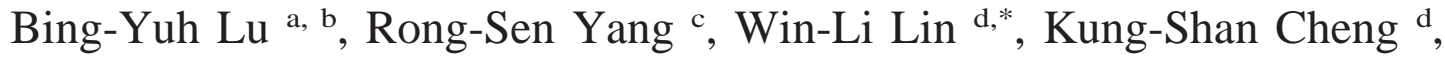 \\ Cheng-Yi Wang ${ }^{\mathrm{d}}$, Te-Son Kuo a, d \\ ${ }^{a}$ Department of Electrical Engineering, National Taiwan University, Taipei, Taiwan, ROC \\ ${ }^{\mathrm{b}}$ Department of Electronic Engineering, Tung-Nan Junior College of Technology, Taipei, Taiwan, ROC \\ ${ }^{\mathrm{c}}$ Department of Orthopedics, National Taiwan University, Taipei, Taiwan, ROC \\ ${ }^{\mathrm{d}}$ Institute of Biomedical Engineering, National Taiwan University, \# 1, Section 1, Jen-Ai Road, Taipei, Taiwan, ROC
}

Received 10 May 1999; received in revised form 9 May 2000; accepted 6 June 2000

\begin{abstract}
This study investigates the optimal external parameters for using an ultrasound applicator for treating bone tumors. This system utilized spherically arranged applicators such as scanned focused ultrasound, and spherically focused multielement applicators. The power deposition pattern is modeled as geometric gain with exponential attenuation. The specific absorption rate ratio (SARR) criteria have been used to determine the proper heating domain of ultrasound driving frequency and therapeutic tumor diameter. The results demonstrate that the optimal driving frequency depends on tumor depth, ultrasound absorption of bone marrow, and diameter of bone, but it is independent of the acoustic window area and SARR. The treatable diameter of bone tumor increased when the absorption ratio of bone marrow to tumor, acoustic window of surface skin, and diameter of bone were elevated. However, the treatable diameter of bone tumor decreased when muscle thickness, SARR of bone tumor site to the surface skin, bone marrow, and bone declined. To deliver the ultrasound energy into the tumor site and to avoid the potential damage to the normal tissue as much as possible, the specific absorption rate $(S A R)$ in the bone tumor site has to be three times higher than that in the surface skin, tumor/marrow, and marrow/bone interfaces. The temperature distributions can verify the $S A R R$ criteria in this model. This study provides the information for choosing the optimal operating frequency of the ultrasound transducer and the acoustic window on the skin surface, and for designing the ultrasound applicator for clinical implementation. (C) 2000 IPEM. Published by Elsevier Science Ltd. All rights reserved.
\end{abstract}

Keywords: Therapeutic domain; Ultrasound hyperthermia; Bone tumor; Optimal driving frequency

\section{Introduction}

Hyperthermia, i.e. heating tumor cells, is a kind of adjuvant cancer therapy. In the previous studies, heating tissues to temperatures above $42^{\circ} \mathrm{C}$ has been shown to kill cells as well as to augment the effects of conventional cancer therapy including radiotherapy and chemotherapy [1-3]. Various kinds of hyperthermia have been developed. Fan et al. [4] reported the preliminary data on treatment of bone tumors with microwave-induced hyperthermia. The bone tumor was dissected from the

* Corresponding author. Tel.: +886-2-23970800x1445; fax: +8862-23940049.

E-mail address: blu@ roc.tnjc.edu.tw (W.-L. Lin). surrounding normal tissues in situ by surgery, and interstitial microwave hyperthermia was employed to destroy the tumor cells. In most of the 62 evaluated cases, the knee joints functioned well, were stable and painless, and retained almost full range of motion. Ikenaga et al. [5] carried out localized hyperthermic treatment of experimental bone tumors with ferromagnetic ceramics in rabbit. The area of tumor necrosis in the hyperthermic therapy group was significantly larger than that in the control group. These studies have shown that hyperthermia is an efficient therapy for treating bone tumors, but complex surgical procedures are involved in the invasive treatment. Charny et al. [6] used a mini-annular phased array to heat human leg by emitting radio frequency energy. They pointed out that the specific absorption rate $(S A R)$ in bone may not be neglected and the specific 
absorption rate ratio $(S A R R)$ of bone to muscle at interface was computed in different angles from the interface in muscle. Oglilvie et al. [7] indicated that the present techniques and equipment utilizing microwave and radio frequency energies appeared to produce largely inadequate heating patterns in superficial or accessible tumors and normal tissues. The advantages of ultrasound techniques have shown promise for delivering controlled heating of both superficial and deep lesions. Although the application of ultrasound energy for hyperthermia is somewhat limited, because it cannot propagate through air cavities and is excessively reflected and absorbed by bone, this modality holds great promise for the controlled heating of superficial and deep lesions.

Bone pain associated with ultrasound hyperthermia treatment for bone tumors is probably caused by extreme temperatures in bone. This can be avoided by sonicating the tumor in such a manner that the intensities at the bone surface are low enough to avoid large temperature elevations. Hynynen et al. [8] pointed out that selection of the proper driving frequency in ultrasound hyperthermia provides the major possible solution to the application of Scanned Focused Ultrasound System (SFUS) treatment in many sites. Therefore, location-oriented treatment planning is necessary for successful clinical utilization of scanned focused ultrasound hyperthermia $[9,10]$. Fujii et al. [11] have studied the reason behind the temperature rise at the muscle-bone interface during ultrasound hyperthermia. They have focused ultrasound energy on the muscle-bone interface to study the incident angle of ultrasound vs. temperature rise and concluded that the bone pain could be reduced if the incident angle can be adjusted to about $15^{\circ}$ or larger than $60^{\circ}$. In addition, Hill [12] has developed a spherical bowl model to optimize acoustic frequency for focused ultrasound surgery. Fry et al. [13] pointed out that similar triangles can be used to determine minimum distance from the focus where spherical theory is applicable. Carstensen et al. [14] have proposed a cone shape model to describe the intensity distribution in an essentially loss medium. They defined geometric gain as $\left(r_{0} / r\right)^{2 a}$ where $r_{0}$ is the radius of curvature of the focused source, $r$ is the distance from the center of radius curvature to the field point, and $a$ models the convergence of the field due to focusing ( $a=0$ for plane wave, $a=1$ for spherical wave). According to these studies, we adopt a cone shape convergent/divergent model (Fig. 1) for the spherically arranged applicators, but not only for a single spherical transducer. The power deposition pattern is modeled as geometric gain with exponential attenuation.

The purpose of this study is to investigate the optimal treatment parameters using a simplified power deposition model [15] of spherically arranged ultrasound applicators to deliver the ultrasound energy into the bone tumor site and to avoid the potential overheating in the normal tissues. The diameter of the acoustic window,

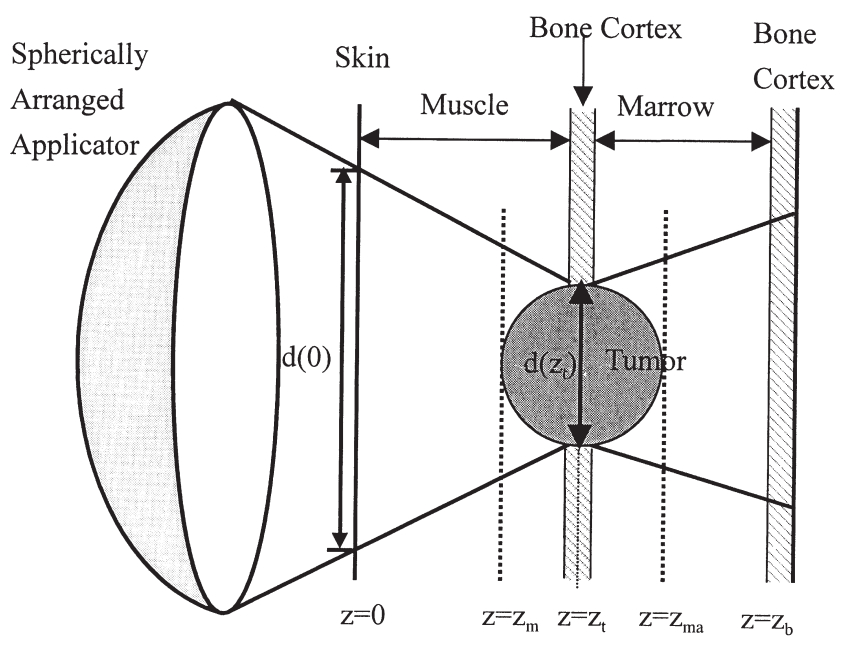

Fig. 1. The hypothetical model of a bone tumor.

tumor size, tumor depth, ultrasound attenuation in the bone tumor tissue, the absorption on the bone, and the driving frequency of transducer have been investigated to determine the appropriate driving frequency for a given tumor depth and tumor size, and to estimate the therapeutic domain for a given acoustic window on the skin surface of the limbs. The results are helpful for the treatment planning and the designing of ultrasound hyperthermic applicators in bone tumor treatment.

\section{Methods}

\subsection{Ultrasound power deposition model}

The anatomic relationship shown in Fig. 1 is the hypothetically spherical tumor that breaks out from the inner side of a long bone. $z$ is defined as the depth from the skin surface while $d(z)$ is the diameter of acoustic window at position $z$. Therefore, $d(0)$ is the diameter of the acoustic window on the skin surface of the limbs and the $d\left(z_{t}\right)$ is the diameter of the focal zone that meets the bone tumor diameter. $z_{\mathrm{ma}}$ and $z_{\mathrm{b}}$ are defined as the depth of the tumor/marrow and the marrow/bone interfaces from the skin surface, respectively. The deposition of the ultrasound energy is modeled as a cone of convergent/divergent shape [12-14]. The ultrasound energy absorbed by the tissues follows the exponential law for attenuation and uniform ideal power deposition within the cone-shape model. In this model, the acoustic power is assumed equal at the same depth within the cone shape region [15]. Then, we have:

$$
\begin{aligned}
& Q(z)=Q(0) \cdot \exp \left\{-2\left[\sum_{i=1}^{4} \mu_{i-1}\left(z_{i-1}-z_{i-2}\right)+\mu_{i}\left(z-z_{i-1}\right)\right]\right\} \\
& \mu_{0}=0, \mu_{1}=\mu_{\mathrm{m}}, \mu_{2}=\mu_{\mathrm{t}}, \mu_{3}=\mu_{\mathrm{ma}}, \mu_{4}=\mu_{\mathrm{b}} \\
& z_{0}=0, z_{1}=z_{\mathrm{m}}, z_{2}=z_{\mathrm{ma}}, z_{3}=z_{\mathrm{b}}
\end{aligned}
$$


where m:muscle, t:tumor, ma:bone marrow, and b:bone cortex

$I(z)=\frac{Q(z)}{A(z)}$

$Q(0)$ denotes the total energy propagating through the acoustic window the area of which is $A(0)=\pi[d(0) / 2]^{2}$. $Q(z)$ is the total energy propagating through the depth $z$. $A(z)$, equal to $\pi[d(z) / 2]^{2}$, is the area of acoustic window at depth $z . \mu_{i}$, the attenuation of specific tissue $(\mathrm{Np} / \mathrm{m})$, is the product of $\alpha_{i}$ and $f . \alpha_{i}$ is the frequency dependent attenuation coefficient of specific tissue $i(\mathrm{~Np} / \mathrm{m} / \mathrm{MHz})$ and $f$ is the driving frequency of the ultrasound transducer $(\mathrm{MHz})$. One hundred percent ultrasound beam transmission into the bone was used in this study to simulate the worst situation. The approximation used in this study overestimated the absorbed power at the bone interface by about 8 to $41 \%$ (the acoustic impedence for muscle is 1.61 to $2.07 \times 10^{6} \mathrm{~kg} / \mathrm{m}^{2} / \mathrm{s}$, and 3.75 to $7.38 \times 10^{6}$ $\mathrm{kg} / \mathrm{m}^{2} / \mathrm{s}$ for bone) [16]. If bone heating can be avoided in these simulations, it should also be possible during clinical treatment. The actual temperature in the bone would be lower than that predicted by the model [17].

\subsection{SAR ratio criteria}

Generally, in ultrasound hyperthermia simulation, all of the attenuated energy has been assumed to be absorbed locally and the scattering has been ignored $[18,19]$. Therefore, the amplitude attenuation coefficient is equal to the absorption coefficient. Hence, we can obtain the ratio of SAR at the tumor depth to that on the acoustic window area as:

$$
\begin{gathered}
\operatorname{SARR}(z, 0)=\frac{\operatorname{SAR}(z)}{\operatorname{SAR}(0)}=\frac{\alpha(z) \cdot I(z)}{\alpha(0) \cdot I(0)}=G G \cdot A R(z, 0) \cdot \exp \\
\left\{-2\left[\left(\sum_{i=1}^{4} \mu_{i-1} \cdot\left(z_{i-1}-z_{i-2}\right)+\mu_{i}\left(z-z_{i-1}\right)\right)\right]\right\}
\end{gathered}
$$

where $\operatorname{SARR}(z, 0)$ is the ratio of $\operatorname{SAR}$ of ultrasound at the depth $z$ to that on the skin surface. $I(0)$ denotes the ultrasound intensity of the acoustic window on the skin surface. $I(z)$ is the ultrasound intensity at depth $z$. AR denotes the absorption ratio of the tissue at depth $z$ (it could be muscle, tumor, bone marrow or bone) to that on the muscle (skin surface). $G G, A(0) / A(z)$, is the geometrical gain, which can overcome the ultrasound attenuation to form the focal zone. $A R(z, 0)$ is the absorption ratio of the tissue at depth $z$ to that on the skin surface. The focus intensity becomes sharper and more convergent with higher $S A R R$ values, and vice versa. The sharpness of the focus pattern decides the therapeutic domain, i.e. the therapeutic domain decreases with the sharper focus pattern. Therefore, we suggest the following $S A R R$ criteria for delivering the ultrasound energy into the tumor site and avoiding the potential damage to the normal tissue as much as possible [15]:

$$
\begin{aligned}
& \operatorname{SARR}\left(z_{\mathrm{t}}, 0\right) \geq 3 \\
& \operatorname{SARR}\left(z_{\mathrm{t}}, z_{\mathrm{ma}}\right) \geq 3 \\
& \operatorname{SARR}\left(z_{\mathrm{t}}, z_{\mathrm{b}}\right) \geq 3
\end{aligned}
$$

Under these three criteria, the $S A R$ in bone tumor site is three times higher than the $S A R \mathrm{~s}$ in skin surface, bone marrow and bone cortex. We expect to enlarge the area of temperature above $42^{\circ} \mathrm{C}$ that covered the tumor and reduce that which covered the normal tissues. This prediction was verified in Fig. 5. In Eqs. (4a), (4b) and (4c), " 3 " is a suggestive value. The influence of different values is shown in Fig. 3(f).

Under the condition of Eq. (4a), from Eq. (3) and the anatomic relationship shown in Fig. 1, let $\mu_{\mathrm{m}}$ equal to $\mu_{\mathrm{t}}$ as the worst case of heating tumor,

$d\left(z_{\mathrm{t}}\right)=\frac{d(0)}{\operatorname{SARR}\left(z_{\mathrm{t}}, 0\right)^{1 / 2}} \cdot \exp \left(\mu_{\mathrm{m}} \cdot z_{\mathrm{t}}\right)$

By considering the SARR of tumor to bone marrow, we can derive,

$$
\begin{aligned}
& \operatorname{SARR}\left(z_{\mathrm{t}}, z_{\mathrm{ma}}\right)=\left(\frac{d\left(z_{\mathrm{ma}}\right)}{d\left(z_{\mathrm{t}}\right)}\right)^{2} \cdot A R(t, m a) \cdot \exp \left(-2 \cdot \mu_{\mathrm{t}} \cdot\left(z_{\mathrm{ma}}\right.\right. \\
& \left.\left.-z_{\mathrm{t}}\right)\right)
\end{aligned}
$$

From the geometrical relationship,

$z_{\mathrm{ma}}=z_{\mathrm{t}}+0.5 \cdot d\left(z_{\mathrm{t}}\right)$

$d\left(z_{\mathrm{ma}}\right)=d\left(z_{\mathrm{t}}\right)+\left(\frac{z_{\mathrm{ma}}-z_{\mathrm{t}}}{z_{\mathrm{t}}}\right) \cdot\left(d(0)-d\left(z_{\mathrm{t}}\right)\right)$

Also, let $\mu_{\mathrm{m}}$ equal to $\mu_{\mathrm{t}}$ then

$$
\begin{aligned}
(1+ & \left.0.5 \cdot \frac{d(0)}{z_{\mathrm{t}}}-0.5 \cdot \frac{d\left(z_{\mathrm{t}}\right)}{z_{\mathrm{t}}}\right)^{2} \cdot \exp \left[\mu_{\mathrm{m}} \cdot d\left(z_{\mathrm{t}}\right)\right] \\
& =\operatorname{SARR}\left(z_{\mathrm{t}}, z_{\mathrm{ma}}\right) \cdot A R(m a, t)
\end{aligned}
$$

By considering the SARR of tumor to bone cortex, we can derive,

$$
\begin{aligned}
& \operatorname{SARR}\left(z_{\mathrm{t}}, z_{\mathrm{b}}\right)=\left[d\left(z_{\mathrm{b}}\right) / d\left(z_{\mathrm{t}}\right)\right]^{2} \cdot A R(t, b) \cdot \exp \left[-2 \cdot \mu_{\mathrm{t}} \cdot\left(z_{\mathrm{ma}}\right.\right. \\
& \left.\left.\quad-z_{\mathrm{t}}\right)\right]
\end{aligned}
$$

According to the geometrical relationship, we have,

$$
\begin{gathered}
\left(1+\frac{z_{\mathrm{b}}-z_{\mathrm{t}}}{z_{\mathrm{t}}}\right) \cdot\left(\frac{d(0)}{d\left(z_{\mathrm{t}}\right)}-1\right) \cdot \exp \left(\mu _ { \mathrm { ma } } \cdot \left(z_{\mathrm{b}}-\left(z_{\mathrm{t}}+\frac{d\left(z_{\mathrm{t}}\right)}{2}\right)\right.\right. \\
\left.+\mu_{\mathrm{m}} \cdot \frac{d\left(z_{\mathrm{t}}\right)}{2}\right)=\left[\operatorname{SARR}\left(z_{\mathrm{t}}, z_{\mathrm{b}}\right) \cdot A R(b, t)\right]^{1 / 2}
\end{gathered}
$$

Eqs. (5), (8) and (10) are used to evaluate the relationship between optimal attenuation or frequency selection and the therapeutic domain for given anatomic conditions and a given acoustic window on skin surface. 


\subsection{Temperature solver}

The temperature distributions are simulated by finite difference technique for calculating the steady-state bioheat transfer equation (BHTE) [20]:

$-\nabla \cdot(k \nabla T)+W C_{\mathrm{b}}\left(T-T_{\mathrm{ar}}\right)=Q$

where $T$ is the tissue temperature, in ${ }^{\circ} \mathrm{C} . k$ is the tissue thermal conductivity, in $\mathrm{W} /\left(\mathrm{m}^{\circ} \mathrm{C}\right)$. It is $0.55 \mathrm{~W} /\left(\mathrm{m}^{\circ} \mathrm{C}\right)$ in soft tissue, and is $1.16 \mathrm{~W} /\left(\mathrm{m}^{\circ} \mathrm{C}\right)$ in bone cortex [2123]. $W$ is the blood perfusion rate, in $\mathrm{kg} /\left(\mathrm{m}^{3} \mathrm{~s}\right)$, and is assumed to be $0 \mathrm{~kg} /\left(\mathrm{m}^{3} \mathrm{~s}\right)$ in bone cortex. $C_{\mathrm{b}}$ is the blood specific heat, in $\mathrm{J} /\left(\mathrm{kg}{ }^{\circ} \mathrm{C}\right)$, is $3770 \mathrm{~J} /\left(\mathrm{kg}{ }^{\circ} \mathrm{C}\right)$ in soft tissue. $T_{\text {ar }}$ is the arterial blood temperature, in ${ }^{\circ} \mathrm{C}$; here it is $37^{\circ} \mathrm{C}$. $Q$ is the power applied via ultrasound, in $\mathrm{W} / \mathrm{m}^{3}$. All boundaries are treated as constant temperature $37^{\circ} \mathrm{C}$ boundary. The outer dimensions of this simulation are $100 \mathrm{~mm}$ acoustic window, $50 \mathrm{~mm}$ muscle depth, 30 $\mathrm{mm}$ bone diameter, and $2 \mathrm{~mm}$ bone cortex thickness and $30 \mathrm{~mm}$ muscle depth behind bone.

\section{Results}

\subsection{Proper heating domain}

The treatable diameters of bone tumor in the condition of muscle attenuation from 0 to $50 \mathrm{~Np} / \mathrm{m}$ are presented in Fig. 2(a). The results simulate a case of $z_{t}=50 \mathrm{~mm}$ and $z_{\mathrm{b}}=80 \mathrm{~mm}$ in Fig. 1. In this case, the diameter of the acoustic window on the skin surface, $d(0)$, is 100 mm. The criteria $\operatorname{SARR}\left(z_{\mathrm{t}}, 0\right) \geqq 3, \operatorname{SARR}\left(z_{\mathrm{t}}, z_{\mathrm{ma}}\right) \geqq 3$, and $\operatorname{SARR}\left(z_{\mathrm{t}}, z_{\mathrm{b}}\right) \geqq 3$ are to achieve a critical heating state. Curves A, B and C represent the Eqs. (5), (8) and (10), respectively. The intersectional area under these three curves is the proper heating domain of the treatment parameters. Hence, this area meets the three criteria of $\operatorname{SARR}\left(z_{\mathrm{t}}, 0\right) \geqq 3, \operatorname{SARR}\left(z_{\mathrm{t}}, z_{\mathrm{ma}}\right) \geqq 3$, and $\operatorname{SARR}\left(z_{\mathrm{t}}, z_{\mathrm{b}}\right) \geq 3$. The dominant criteria for the proper heating domain in Fig. 2(a) are curves $\mathrm{A}$ and $\mathrm{C}$. There is a peak, $(26.3,15.5)$, in this intersectional area. This peak is the maximum therapeutic tumor diameter $\left(\operatorname{Max}\left(d\left(z_{\mathrm{t}}\right)\right)\right.$ which meets the three criteria in Eqs. (4a), (4b) and (4c). The corresponding attenuation is called the optimal attenuation $\left(\mu_{\mathrm{opt}}\right)$ indicating the optimal driving frequency $\left(f_{\text {opt }}\right)$ for the maximum therapeutic tumor diameter. Hence, the optimal driving frequency is the one to be used for obtaining the $\operatorname{Max}\left(d\left(z_{\mathrm{t}}\right)\right)$ when the $z_{\mathrm{t}}, z_{\mathrm{b}}, d(0)$ and other anatomic properties are given. Assuming that the attenuation coefficients of muscle, tumor, bone marrow and bone are 10, 10, 10 and $300 \mathrm{~Np} / \mathrm{m} / \mathrm{MHz}$, respectively, this peak means that the maximum treatable diameter of bone tumor is $15.5 \mathrm{~mm}$ using the optimal driving frequency, 2.63 MHz. Applying these two therapeutic parameters under the conditions described above, we can get the $S A R R$ distribution presented in Fig. 2(b).

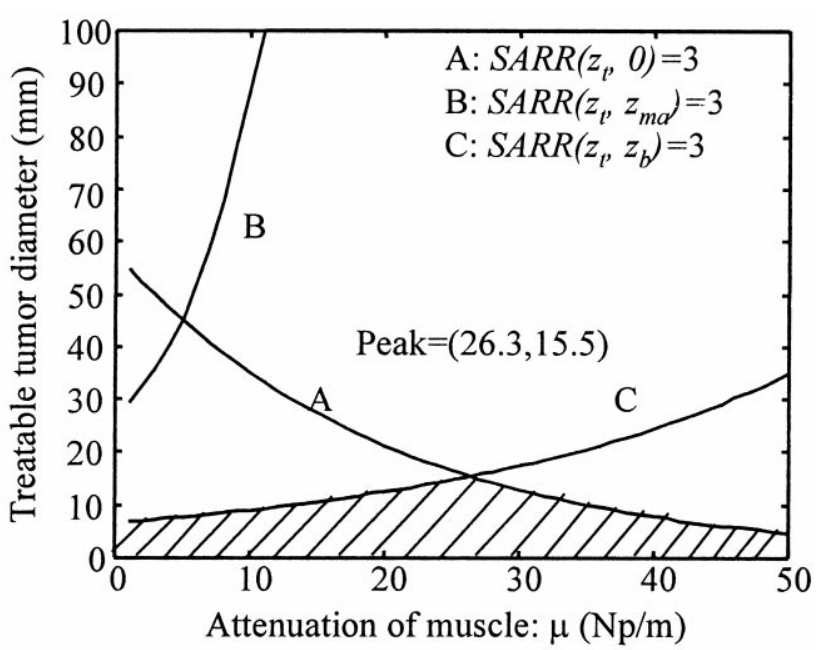

(a)

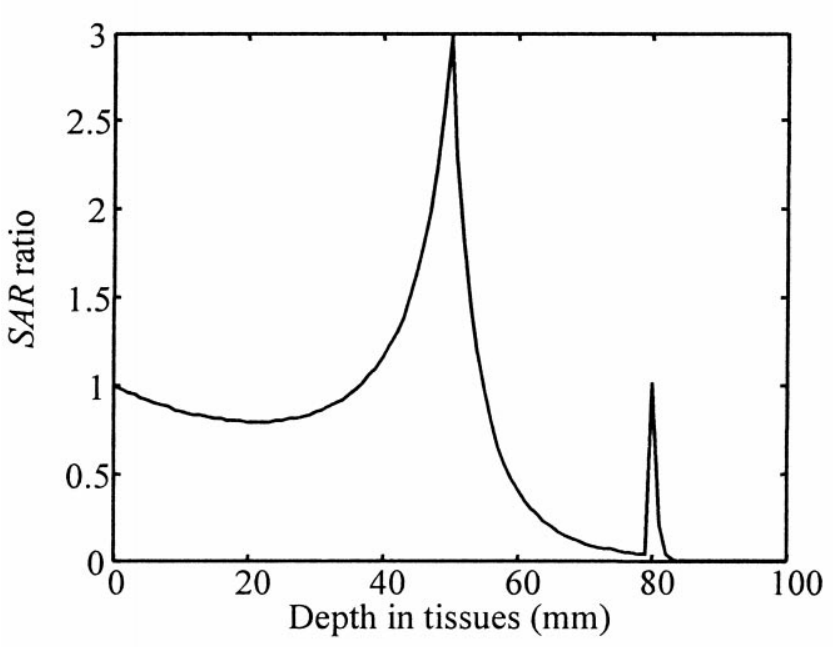

(b)

Fig. 2. The proper heating domain: the typical parameters are $d(0)=100 \mathrm{~mm}, z_{\mathrm{t}}=50 \mathrm{~mm}, z_{\mathrm{b}}=80 \mathrm{~mm}, \mu_{\mathrm{ma}}=\mu_{\mathrm{m}}=\mu_{\mathrm{t}}, \mu_{\mathrm{b}}=30 \cdot \mu_{\mathrm{m}}$, (a) A: $\operatorname{SARR}\left(z_{\mathrm{t}}, 0\right)=3, \mathrm{~B}: \operatorname{SARR}\left(z_{\mathrm{t}}, z_{\mathrm{ma}}\right)=3$ and C: $\operatorname{SARR}\left(z_{\mathrm{t}}, z_{\mathrm{b}}\right)=3$. The intersectional area (shaded area) under the 3 curves is the proper heating domain of treatment parameters. That is $\operatorname{SARR}\left(z_{\mathrm{t}}, 0\right) \geqq 3$, $\operatorname{SARR}\left(z_{\mathrm{t}}, z_{\mathrm{ma}}\right) \geqq 3$ and $\operatorname{SARR}\left(z_{\mathrm{t}}, z_{\mathrm{b}}\right) \geqq 3$; (b) The $\operatorname{SAR}$ ratio distribution: it meets $\operatorname{SARR}\left(z_{\mathrm{t}}, 0\right)=3, \operatorname{SARR}\left(z_{\mathrm{t}}, z_{\mathrm{ma}}\right) \geqq 3$ and $\operatorname{SARR}\left(z_{\mathrm{t}}, z_{\mathrm{b}}\right)=3$.

To observe the effects of the absorption ratio of tumor to bone marrow $(A R(m a, t))$, tumor location, diameter of acoustic window on skin surface, bone diameter, and $S A R R$ on the treatable diameter of tumor, we change each individual parameter while keeping the others constant in the following discussion. The typical parameters in this work are $d(0)=100 \mathrm{~mm}, z_{\mathrm{t}}=50 \mathrm{~mm}, z_{\mathrm{b}}=80 \mathrm{~mm}$ $\left(D_{\mathrm{b}}=30 \quad \mathrm{~mm}\right), \quad \operatorname{SARR}\left(z_{\mathrm{t}}, 0\right) \geqq 3, \quad \operatorname{SARR}\left(z_{\mathrm{t}}, z_{\mathrm{ma}}\right) \geqq 3$, $\operatorname{SARR}\left(z_{\mathrm{t}}, z_{\mathrm{b}}\right) \geqq 3, A R(m, t) A R(m a, t)=1$, and $A R(b, t)=30$. 


\subsection{Absorption ratio of tumor to bone marrow}

Owing to the uncertain percentage of the bone trabeculi in bone marrow resulting in the uncertain attenuation coefficient of bone marrow, it is necessary to estimate the different absorption ratio of tumor to bone marrow. Let $A R(m a, t)$ be in the range of 0.5 to 2.0 and others be the typical parameters, we can investigate the effects of $A R(m a, t)$ to $\operatorname{Max}\left(d\left(z_{\mathrm{t}}\right)\right)$. The peaks in Fig. 3(a) are (31.0, 11.9), (26.3, 15.5), (23.1, 18.0), and $(0,0)$ for the $A R(m a, t)=0.5,1.0,1.5$, and 2.0 , respectively. If $A R(m a, t) \geqq 2.0$, it cannot meet the $\operatorname{SARR}\left(z_{\mathrm{t}}, z_{\mathrm{ma}}\right) \geqq 3$ criterion. Let $d(0)=100 \mathrm{~mm}, z_{\mathrm{t}}=50 \mathrm{~mm}, z_{\mathrm{b}}=80 \mathrm{~mm}\left(D_{\mathrm{b}}=30\right.$ $\mathrm{mm}), A R(m, t)=1$, and $A R(b, t)=30$, we can investigate the effects of $A R(m a, t)$ to $\operatorname{Max}\left(d\left(z_{\mathrm{t}}\right)\right)$. Here, we skip the $\operatorname{SARR}\left(z_{\mathrm{t}}, z_{\mathrm{ma}}\right) \geqq 3$ criterion and obtain the results in Fig. 3 (b). The peaks are $(26.3,15.5),(21.0,20.1),(18.0,23.5)$, (16.1,26.0), and $(14.0,28.0)$ for the $A R(m a, t)=1,2,3,4$, and 5 , respectively.

\subsection{Tumor location}

Setting the parameters for typical conditions, we vary the tumor depth $\left(z_{\mathrm{t}}\right)$ to investigate the effects of tumor depth $\left(z_{\mathrm{t}}\right)$ on $\operatorname{Max}\left(d\left(z_{\mathrm{t}}\right)\right)$ and $\mu_{\mathrm{opt}}$. The relationship between the therapeutic tumor diameter $\left(d\left(z_{\mathrm{t}}\right)\right)$ and the attenuation $(\mu)$ for the tumor located at different depth is depicted in Fig. 3(c). The peaks, represented by $\left(\mu_{\mathrm{opt}}\right.$, $\left.\operatorname{Max}\left(d\left(z_{\mathrm{t}}\right)\right)\right)$, are $(27.2,19.0),(26.3,15.5),(24.9,12.7)$ and $(24.0,10.6)$ for $z_{\mathrm{t}}=40,50,60$ and $70 \mathrm{~mm}$, respectively. The aforementioned curves demonstrate that the attenuation for those peaks, $\mu_{\text {opt }}$ and $\operatorname{Max}\left(d\left(z_{t}\right)\right)$, decreases with the tumor depth $\left(z_{\mathrm{t}}\right)$. The areas under the curves $\mathrm{A}$ to $\mathrm{E}$ in Fig. 3(c) meet the three criteria. In curve F, the attenuation of muscle $\leqq 12 \mathrm{~Np} / \mathrm{m}$ cannot meet the criterion $\operatorname{SARR}\left(z_{\mathrm{t}}, z_{\mathrm{ma}}\right) \geqq 3$. When the attenuation $\leqq 12 \mathrm{~Np} / \mathrm{m}$, the area between $\mathrm{F} 1$ and $\mathrm{F} 2$ meet the three $S A R R$ criteria.

\subsection{Diameter of acoustic window on skin surface}

Figure $3(\mathrm{~d})$ provides the simulation results revealing that the optimal attenuation is independent of the acoustic window on skin surface with the typical parameters in this work. As seen in this figure, when $\mu_{\text {opt }}$ is maintained at $26.3 \mathrm{~Np} / \mathrm{m}, \operatorname{Max}(d(0)) \mathrm{s}$ are $0,0,11.4,15.5$ and $19.0 \mathrm{~mm}$ for $d(0) \mathrm{s}$ being $25,50,75,100$, and 125 $\mathrm{mm}$, respectively.

\subsection{Bone diameter}

We have observed the effects of bone diameter $\left(D_{\mathrm{b}}\right)$ to $\operatorname{Max}\left(d\left(z_{\mathrm{t}}\right)\right)$ and $\mu_{\text {opt }}$ by changing the $D_{\mathrm{b}}$ value. In Fig. $3(\mathrm{e}), \mu_{\text {opt }}$ decreases with the $D_{\mathrm{b}}$, but $\operatorname{Max}\left(d\left(z_{\mathrm{t}}\right)\right)$ increases with $D_{\mathrm{b}}$. The peaks are $(50.0,4.0),(35.3,9.7),(26.3,15.5)$, and $(20.9,20.4)$ for the $D_{\mathrm{b}}=10,20,30$, and $40 \mathrm{~mm}$, respectively. The larger $D_{\mathrm{b}}$ causes more absorption in bone marrow to reduce power delivery to bone, so the criteria, $\operatorname{SARR}\left(z_{\mathrm{t}}, z_{\mathrm{b}}\right) \geqq 3$, are loosened to increase the $d\left(z_{\mathrm{t}}\right)$. This indicates that a lower driving frequency should be used for larger $D_{\mathrm{b}}$. In addition, $\operatorname{Max}\left(d\left(z_{\mathrm{t}}\right)\right)$ becomes larger as $D_{\mathrm{b}}$ increases.

\section{6. $S A R R$}

To examine the effects of $A R(m a, t)$ on $\operatorname{Max}\left(d\left(z_{\mathrm{t}}\right)\right)$, we have changed the $S A R R$ value while keeping the other parameters at typical values. As seen in Fig. 3(f), when $\mu_{\text {opt }}$ is maintained at $26.3 \mathrm{~Np} / \mathrm{m}, \operatorname{Max}\left(d\left(z_{\mathrm{t}}\right)\right)$ is $27.7,18.9$, $15.5,13.1$, and $11.8 \mathrm{~mm}$ for $\operatorname{SARR}(t, m)=\operatorname{SARR}(t$, $m a)=S A R R(t, b)=1,2,3,4$, and 5, respectively. This reveals that $\mu_{\mathrm{opt}}$ is independent of $S A R R$. If we set $S A R R>4$ as the effective heating, the optimal frequency for therapy will not be changed.

\subsection{Temperature distributions}

Under the three $\operatorname{SARR}$ criteria, $\operatorname{SARR}\left(z_{\mathrm{t}}, 0\right) \geqq 3$, $\operatorname{SARR}\left(z_{\mathrm{t}}, z_{\mathrm{ma}}\right) \geqq 3$ and $\operatorname{SARR}\left(z_{\mathrm{t}}, z_{\mathrm{b}}\right) \geqq 3$, there is a low level of $S A R R$ distribution in the tumor/marrow interface. In other words, tumor cells near the tumor/marrow interface cannot receive adequate ultrasound energy to achieve hyperthermic therapeutic effect. However, the highest temperature point in the focal zone transfers heat to the tumor/marrow interface. The temperature contour distributions of different blood perfusions in tissues and $A R(m a, t)$ s are displayed in Fig. 4. The area of which temperature is higher than $42^{\circ} \mathrm{C}$ covers not only the whole tumor but also part of muscle and bone marrow. The temperature distribution depends on the SARR distribution, blood perfusion in tissues, and thermal conductivity of tissues. Assuming that $\mu_{\mathrm{b}}$ is 30 times $\mu_{\mathrm{m}}, \mu_{\mathrm{ma}}$ is $0.5,1,3$, and 5 times $\mu_{\mathrm{m}}$, we specify the blood perfusion in muscle and blood perfusion in bone marrow as shown in Fig. 5. To find the SARR distributions in the four different $\mu_{\text {ma }}$, the temperature distributions were simulated in 12 cases by BHTE to make all the highest temperature in tumor be $45^{\circ} \mathrm{C}$. The percentages of tumor $>42^{\circ} \mathrm{C} /$ tumor, muscle $>42^{\circ} \mathrm{C} /$ muscle, bone marrow $>42^{\circ} \mathrm{C} /$ bone marrow, and bone $>42^{\circ} \mathrm{C} /$ bone in the cone are shown in Fig. 5. We can find that higher attenuation and lower blood perfusion in bone marrow may achieve $100 \%>42^{\circ} \mathrm{C}$ of tumor.

\section{Discussion}

In this study, we utilized a model to investigate the optimal frequency and therapeutic domain for application of ultrasound hyperthermia to bone tumor treatment. The results have demonstrated that in spite of the high ultrasound absorption of bone, the temperature in bone cortex is not high (Figs. 4 and 5). As compared to 


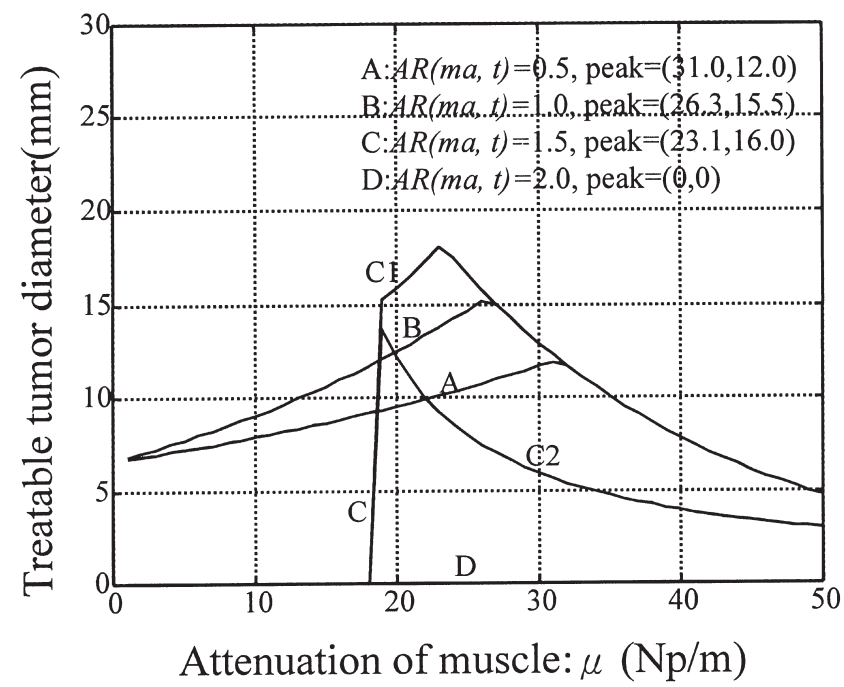

(a)

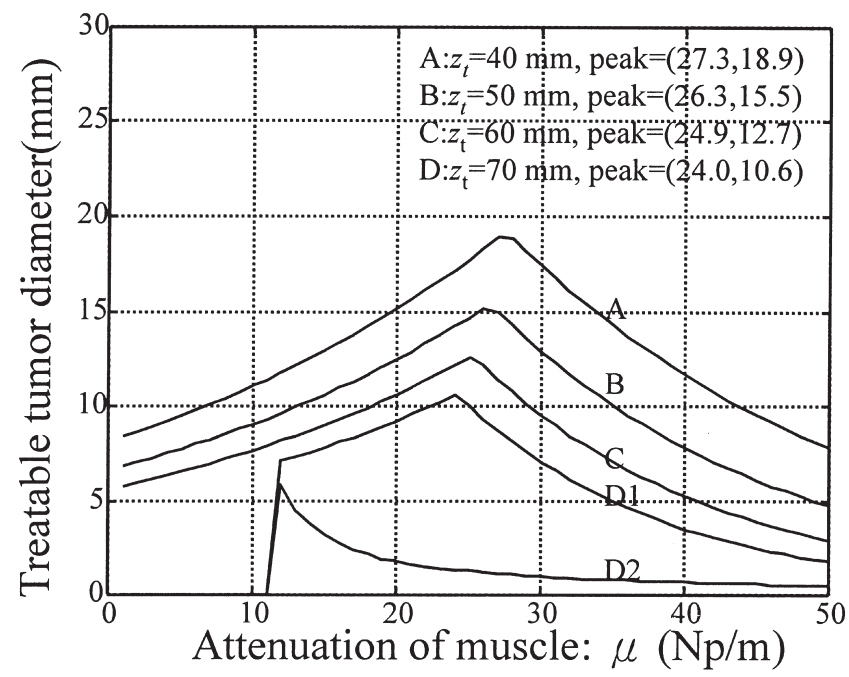

(c)

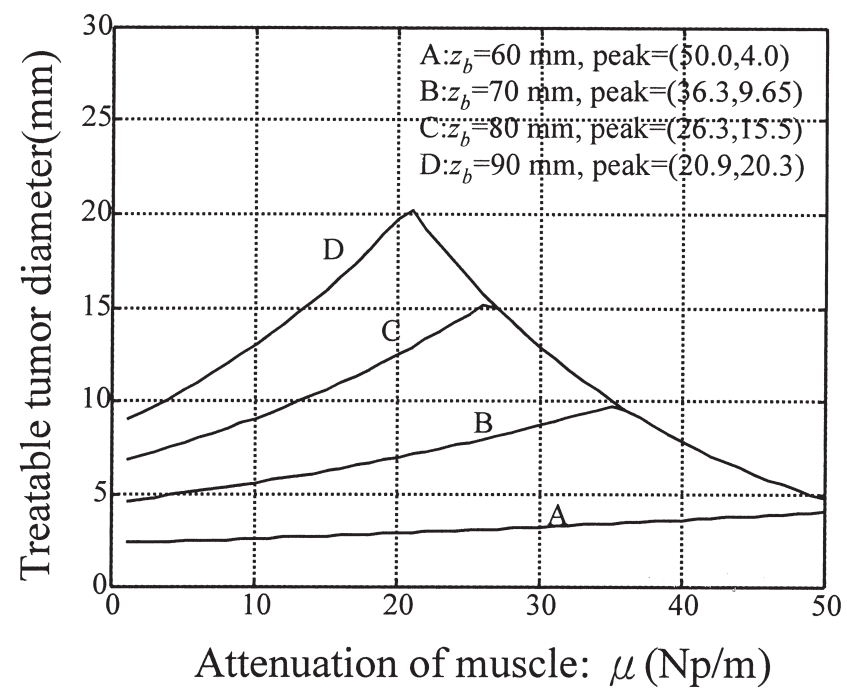

(e)

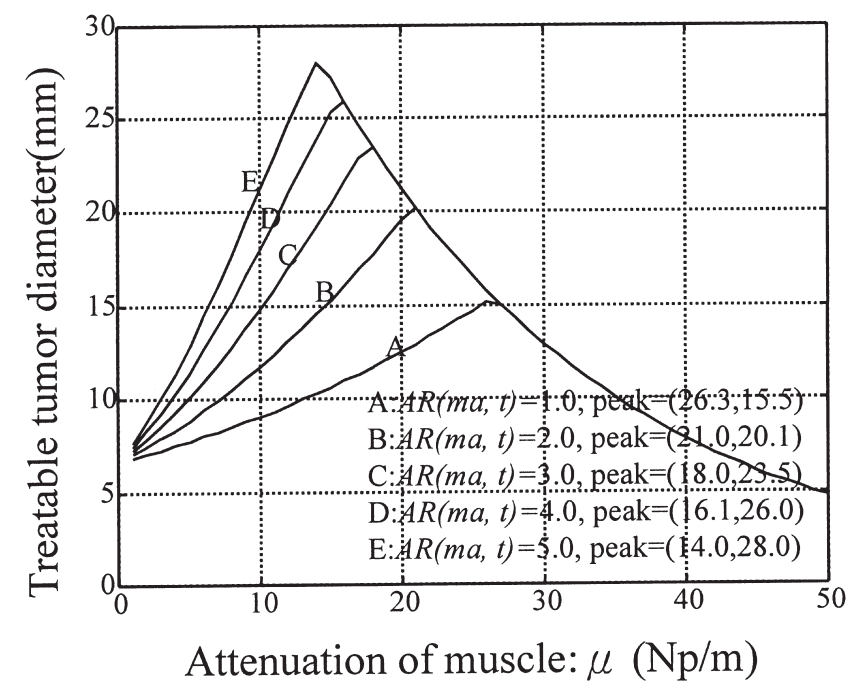

(b)

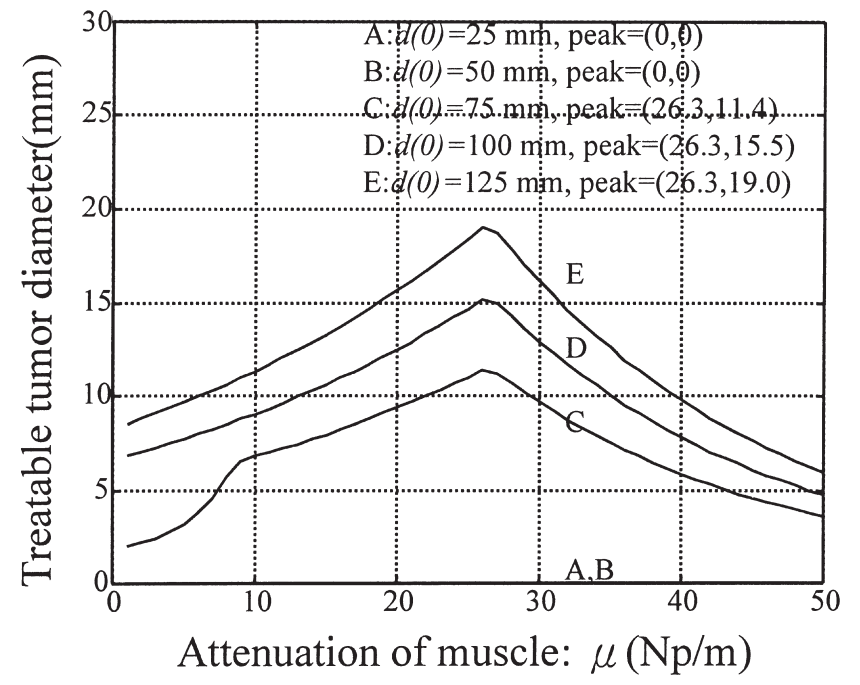

(d)

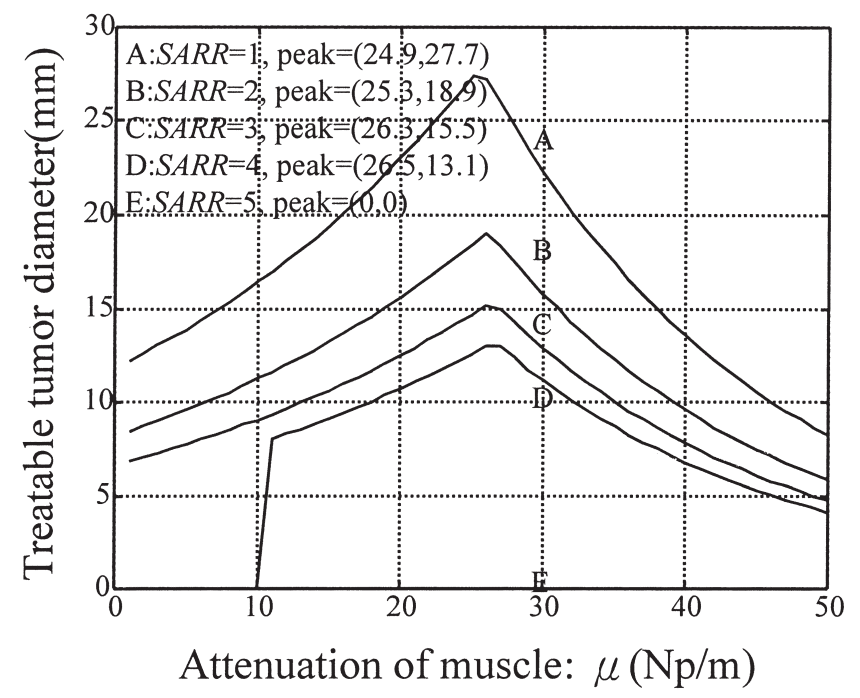

(f)

Fig. 3. The effect of parameters $\left(A R(\mathrm{ma}, \mathrm{t}), z_{\mathrm{t}}, d(0), S A R R\right.$, and $\left.z_{\mathrm{b}}\right)$ on therapeutic tumor diameter and optimal attenuation: (a) $A R($ ma,t $)<2.0 ;(\mathrm{b})$ $A R(\mathrm{ma}, \mathrm{t}) \geqq 2.0$; (c) $z_{\mathrm{t}}$; (d) $z_{\mathrm{b}}$; (f) $S A R R$. (The typical parameters in this work are $d(0)=100 \mathrm{~mm}, z_{\mathrm{t}}=50 \mathrm{~mm}, z_{\mathrm{b}}=80 \mathrm{~mm}\left(D_{\mathrm{b}}=30 \mathrm{~mm}\right), S A R R\left(z_{\mathrm{t}}, 0\right) \geqq 3$, $\operatorname{SARR}\left(z_{\mathrm{t}}, z_{\mathrm{ma}}\right) \geqq 3, \operatorname{SARR}\left(z_{\mathrm{t}}, z_{\mathrm{b}}\right) \geqq 3, A R(\mathrm{~m}, \mathrm{t}) \operatorname{AR}(\mathrm{ma}, \mathrm{t})=1$, and $\left.A R(\mathrm{~b}, \mathrm{t})=30\right)$. 

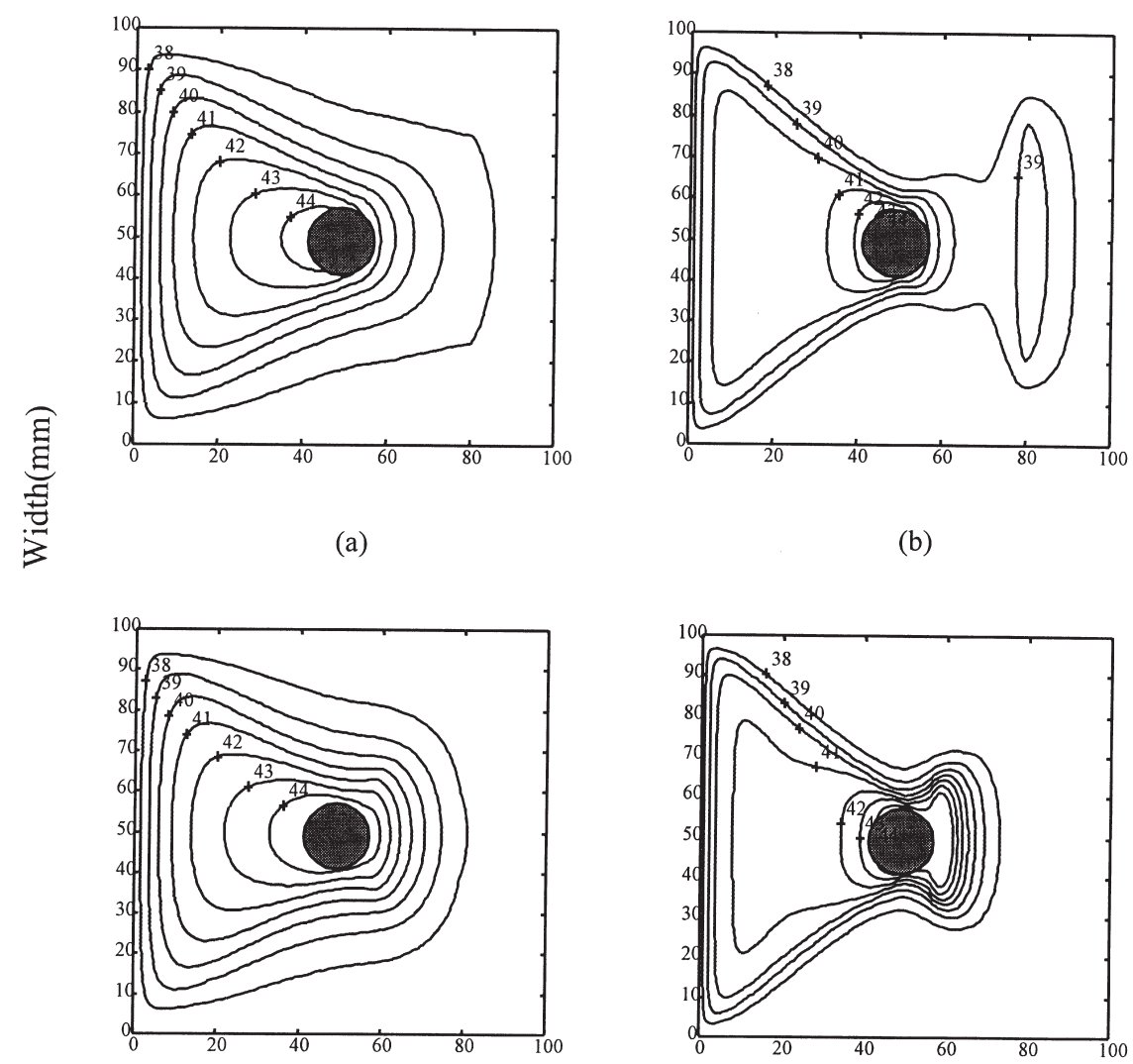

(b)

(c)

$\operatorname{Depth}(\mathrm{mm})$

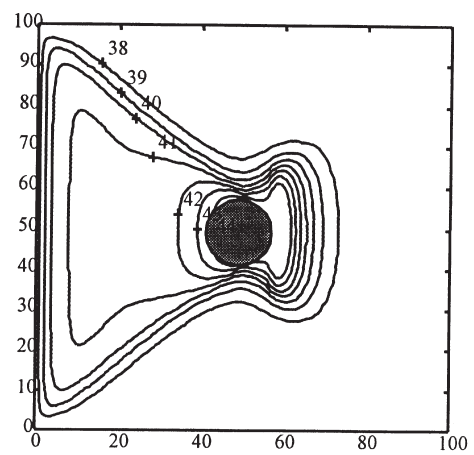

(d)

Fig. 4. The contour of temperature distribution, here, $z_{\mathrm{t}}=50 \mathrm{~mm}, z_{\mathrm{b}}=80 \mathrm{~mm}, d(0)=100 \mathrm{~mm}$ and $\mathrm{W}$ of bone $=0 \mathrm{~kg} / \mathrm{m}^{3} / \mathrm{s}$. The shading area represents hypothetical tumor: (a) $A R(m a, t)=0.5, W$ of muscle $=1.0 \mathrm{~kg} / \mathrm{m}^{3} / \mathrm{s}$, and $W$ of marrow $=0.5 \mathrm{~kg} / \mathrm{m}^{3} / \mathrm{s}$, (b) $A R(m a, t)=0.5, W$ of muscle $=10 \mathrm{~kg} / \mathrm{m}^{3} / \mathrm{s}$, and $W$ of marrow $=0.5 \mathrm{~kg} / \mathrm{m}^{3} / \mathrm{s}$, (c) $A R(m a, t)=5.0, W$ of muscle $=1 \mathrm{~kg} / \mathrm{m}^{3} / \mathrm{s}$, and $W$ of marrow= $0.5 \mathrm{~kg} / \mathrm{m}^{3} / \mathrm{s}$, (d) $A R(m a, t)=5.0, W$ of muscle $=10 \mathrm{~kg} / \mathrm{m}^{3} / \mathrm{s}$, and $W$ of marrow $=1 \mathrm{~kg} / \mathrm{m}^{3} / \mathrm{s}$.

the soft tissue, the bone has a higher thermal conductivity. Besides, the bone marrow absorbs a certain amount of ultrasound energy. Therefore, overheating could occur in marrow, but seldom in bone. Such a heating condition may provide a guide for predicting the optimal condition for applying ultrasound hyperthermia to treating bone tumors. From this model, the proper driving frequency, the acoustic window size, i.e. the size of applicators and the radiation direction, of these systems for treating bone tumors can be decided. Therefore, this model is very helpful to planning the clinical treatment.

Ultrasound hyperthermia has been successfully employed to treat the tumors of various sites [17,24]. Most well established models of ultrasound hyperthermia have been used to investigate the treatment of soft tissue tumors. Bone tumors are unique in their special characteristics of impedance of ultrasound transmission and high ultrasound absorption during the application of ultrasound hyperthermia. These problems have to be compensated for in order to maximize therapeutic delivery. Therefore, proper design of the model remains the key to successful treatment. The basic requisites of a successful ultrasound hyperthermia therapy include the total deposition of energy in the tumor tissue and minimal damage of the normal tissue. Using the present model of ultrasound hyperthermia model, we can achieve $42^{\circ} \mathrm{C}$ in the bone tumor tissue and cause minimal damage to the surrounding normal tissues. Therefore, the therapeutic effect can be achieved without causing serious damage to the surrounding normal tissues.

Bone marrow refers to the tissue occupying the cavities between the trabecular bone. Normal marrow is either red, containing the haematopoietic elements, or yellow, composed mainly of fat cells [25]. The marrow in diaphysis contains more fat while that in metaphysis contains more bone trabeculi. Therefore, we can assume that the ultrasound absorption of marrow in diaphysis is close to that in fat $(A R(m a, t)=0.5)$ and the marrow in metaphysis has a higher ultrasound absorption coefficient. A potential problem is that there is little experimental data available regarding the ultrasound absorption of bone marrow. For bovine trabecular bone, replacement of marrow by water caused a reduction in 

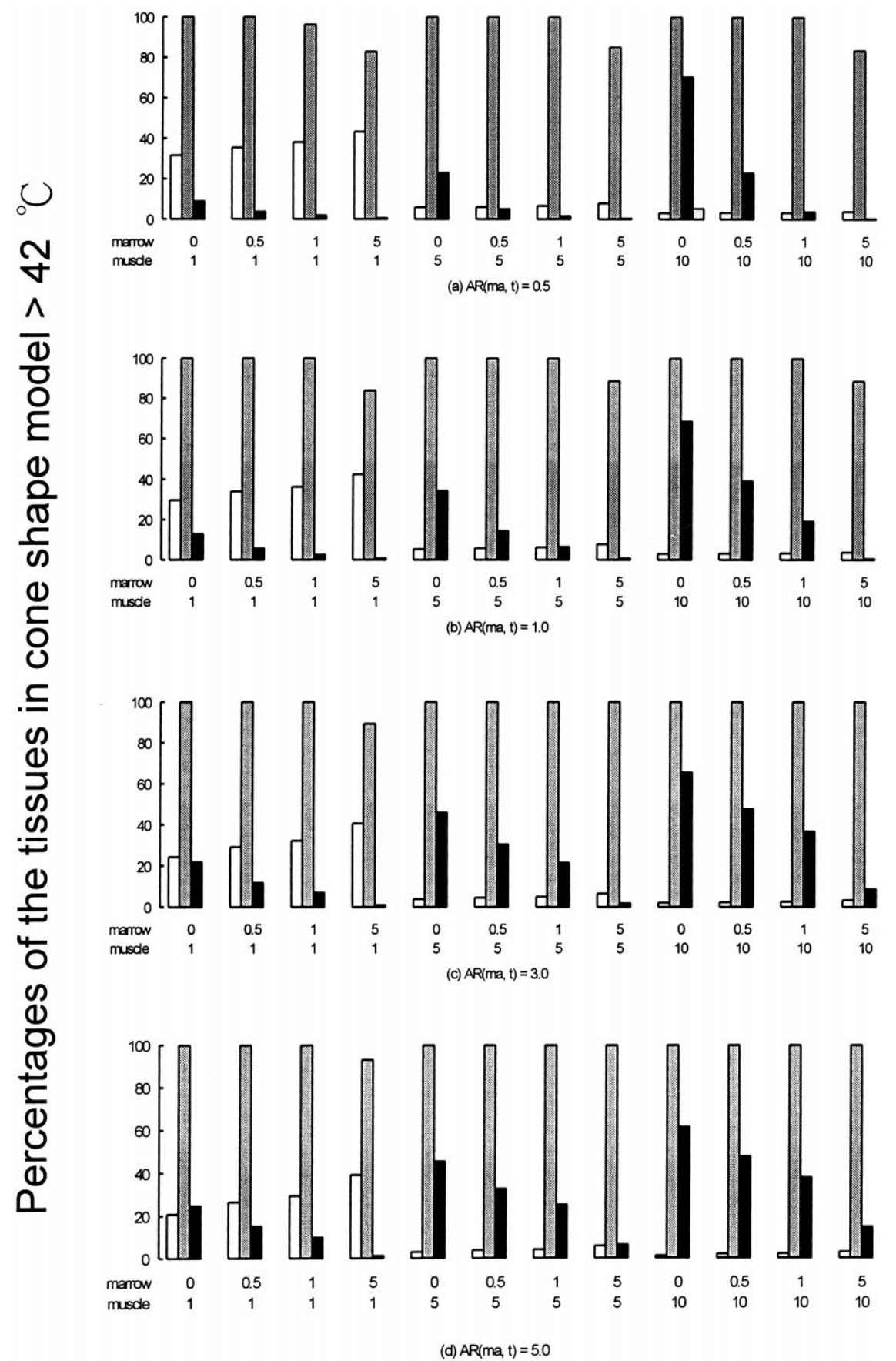

Omusde $\square_{\text {tumar }}$ marow $\square_{\text {bone }}$

\section{Blood perfusion $\left(\mathrm{kg} / \mathrm{m}^{3} / \mathrm{s}\right)$}

Fig. 5. The percentages of tumor $>42^{\circ} \mathrm{C} /$ tumor, muscle $>42^{\circ} \mathrm{C} /$ muscle, bone marrow $>42^{\circ} \mathrm{C} /$ bone marrow, and bone $>42^{\circ} \mathrm{C} /$ bone in the cone (assuming the blood perfusion of bone=0): (a) $A R(m a, t)=0.5$, (b) $A R(m a, t)=1.0$, (c) $A R(m a, t)=3.0$, and (d) $A R(m a, t)=5.0$.

the mean specific differential attenuation $(S D A)$ of 2.0 $\mathrm{dB} / \mathrm{cm} / \mathrm{MHz}$ and $5.0 \mathrm{~dB} / \mathrm{cm} / \mathrm{MHz}$ for the $500 \mathrm{kHz}$ and $1 \mathrm{MHz}$ transducer pairs, respectively [26]. We estimate $A R(m a, t)=0.5$ to 5.0 in Fig. 3(a) and (b) showing that $\mu_{\text {opt }}$ decreases with the $A R(m a, b)$, while $\operatorname{Max}\left(d\left(z_{\mathrm{t}}\right)\right)$ increases with $A R(m a, t)$. Therefore, the treatable diam- eter of tumor in the metaphysis is greater than that in the diaphysis. From another point of view, the diameter of the metaphysis is greater than that of the diaphysis in the long bone. As shown in Fig. 3(e), the treatable diameter of bone tumor increased with a larger bone diameter. Thus, the treatable diameter of tumor in the metaphysis 
is greater than that in diaphysis. According to these two results, we can conclude that the treatable diameter of tumor in the metaphysis is greater than that in the diaphysis.

The blood perfusion of bone marrow was assumed to be 0 to $5 \mathrm{~kg} / \mathrm{m}^{3} / \mathrm{s}$ in this study [16]. As aforementioned in the long bone, the blood perfusion in the metaphysis could be higher than that in the diaphysis. Therefore, in the metaphysis, bone marrow has higher $A R(m a, t)$ and blood perfusion; while in the diaphysis, bone marrow has lower $A R(m a, t)$ and blood perfusion. In Fig. 5, we found that the lower blood perfusion ratio of bone marrow to muscle and the higher $A R(m a, t)$ can easily achieve $100 \%$ tumor therapeutic percentage. From this point of view, the blood perfusion and $A R(m a, t)$ are in the trade-off state for ultrasound hyperthermia application in the diaphysis and metaphysis.

The therapeutic parameters in this work are driving frequency of ultrasonic applicators and acoustic window on the surface skin (Fig. 3). The variations in blood perfusion and attenuation coefficient in Fig. 5 are used to verify the SARR criteria, and not as controllable parameters to be optimized. In fact, blood perfusion can be a controllable parameter in hyperthermia. For example, Vertrees et al. had developed the venovenous perfusion and temperature monitoring system. Blood was drained from the jugular vein, pumped through a servo-regulated heat exchange system, with controlled flow, and reinfused into the femoral vein [27].

For a planar 1D array, $G G=1$ [13]. The effect of power convergence is worse than that for a 2-D convergent system. Hence, for a spherical 2-D phased array, if the power is converged by the in-phase method, the waveform is similar to that of the spherical transducer. So the $G G$ equals $(d(0) / d(z))^{2}$. In this viewpoint, the model in this work can be approached to the spherical 2-D phased array. Moreover, it is useful to employ the 0.5 to $1.0 \mathrm{MHz} 2-\mathrm{D}$ phased arrays for treating the deepseated tumor in homogeneous tissue. However, in our study, the aforementioned driving frequencies are relatively low. Overheating in bone cortex cannot be avoided because of the low attenuation in soft tissue by adjusting the amplitude and relative phase of the elements in these arrays. One of the better ways for optimization is to select the higher resonant frequency elements in the phased array. Therefore, this study supports an inverse method for finding the optimal frequency range for treating bone tumor treatment.

Fujii et al. [11] have indicated that at incident angles larger than the critical angle of the transversal wave, no temperature rise results from the ultrasound absorption bone; the incident longitudinal wave, strengthened by the reflected wave, is absorbed in the muscle and is transported to the interface, so that the temperature of the interface and bone increases slightly. They have designed the experiment to focus on the ultrasound power at the muscle-bone interface. The experimental results show that when the incident angle $=40^{\circ}$, the temperature rises about $14^{\circ} \mathrm{C}$ at the interface. In our study, the ultrasound power is focused on the tumor site. The power at the muscle-bone interface is relatively small as compared to that in the focal zone. Therefore, if the incident angle is also $40^{\circ}$, the temperature rise should be much smaller than $14^{\circ} \mathrm{C}$. Furthermore, the model in this work covered the various incident angles within the acoustic window, and the approximation used in this study overestimated the absorbed power at the bone interface by about 8 to $41 \%$. If bone heating can be avoided in these simulations, it should also be possible during clinical treatment. The actual temperature in the bone would be lower than predicted by the model [17].

In this study, we use the SARR criteria to estimate the therapeutic parameters, but not temperature distributions. However, McGough et al. pointed out that the BHTE has the property of the spatial low-pass filter effect [28]. Although the temperature is not exactly proportional to $Q(S A R)$, the temperature distribution can be estimated from the SAR distribution. Charny et al. [6] applied a mini-annular phased array to treating human leg with emitting radio frequency energy. The design of this phased array tries to maximize the SAR i.e. energy deposition, in the central area. The heating results were presented in SAR distribution. Ebbini and Cain have presented a field optimization method which concentrates power at a focal point and reduces interference patterns (hot spot) elsewhere to treat deep-seated tumor in homogeneous tissue [29]. Therefore, we can use the $S A R$ distribution to estimate the temperature distribution. Fig. 5 verifies that the $S A R R$ criteria support the proper temperature distributions.

However, the model in this work cannot calculate the precise ultrasound intensity field as the Rayleigh-Sommerfield diffraction integral method [24] or source point method [30]. But, it is helpful to estimate the operating frequency and the size of ultrasound transducers quickly, especially in the multilayer tissue cases. Further investigation is needed for the evaluation of its potential clinical applications. For the moving energy of focus scanning ultrasound hyperthermic system, it is reasonable to average temporally the absorption energy in tissue to neglect roughly the interference phenomenon in a steady state. Therefore, this model can represent geometric convergent focused and spherically arranged hyperthermic applicators such as the SFUS, and spherically segmented arrays [31-33], but not necessarily a single focused applicator. The simulations of temperature distribution in these systems are very complex. For example, the power array in SFUS has to be tilted, rotated, translated and convoluted to obtain the power distributions [18]. If the resonant frequency is changed, the procedures described above have to restart. Therefore, it is time-consuming, especially in the multi-layered tissues, to find the optimal 
driving frequency by changing the control parameters in these systems. The present model supports an easy and rapid theoretical estimation for the range of optimal driving frequency in these systems. The results in Fig. 3 are helpful for estimating quickly whether the bone tumor is treatable in the multilayer tissue condition, to choose the optimal operating frequency of ultrasound transducer and the acoustic window on the skin surface when the tumor size, tumor depth, and bone diameter are known, and to design an optimal ultrasound applicator for bone tumors.

\section{Conclusion}

This study employs a model with a simplified ultrasound beam form model to examine the optimal driving frequency and treatable domain formed by the tumor size and tumor depth and to simulate the $S A R$ distribution for the hyperthermic treatment of a bone tumor. The results demonstrate that the treatable diameter of a bone tumor increases with the absorption ratio of bone marrow to tumor, acoustic window of surface skin, and diameter of bone, but decreases with muscle depth, and SAR ratio of bone tumor site to the surface skin, bone marrow, and bone. Besides, the optimal driving frequency depends on the tumor depth, ultrasound absorption of bone marrow, and bone diameter, but is independent on the acoustic window area and SAR ratio under the three SARR criteria. The results are helpful for estimating rapidly whether the bone tumor is treatable in the multilayer tissue condition, to choose the optimal operating frequency of the ultrasound transducer and the acoustic window on the skin surface when the tumor size, tumor depth, and bone diameter of bone are known, and to design ultrasound applicators, such as SFUS, and spherically segmented arrays for treating bone tumors. Therefore, this model is very helpful for planning the clinical treatment with these systems.

\section{Acknowledgements}

The authors thank the National Science Council and the Department of Health of the Republic of China for partially supporting this research, NSC 87-2213-E-002075 and DOH 87-HR-635.

\section{References}

[1] Seegenschmiedt MH, Feldmann HJ. Clinical rationale for thermoradiotherapy. In Seegenschmiedt MH, Feldmann HJ, Vernon CC, editors. Thermoradiotherapy and Thermochemotherapy, vol. 2 . Berlin/Heidelberg/New York: Springer-Verlag, 1995:3-23.

[2] Overgaard J. The current and potential role of hyperthermia in radiotherapy. Int J Radiat Oncol Biol Phy 1989;16:535-49.
[3] Vernon CC, Hand JW, Field SB, Machin D, Whaley JB, van der Zee J, van Putten WL, van Rhoon GC, van Dijk JDP, Gonzalez DG, Liu FF, Goodman P, Sherar M. Radiotherapy with or without hyperthermia in the treatment of superficial localized breast cancer: results from five randomized controlled trials. Int J Radiat Oncol Biol Phys 1996;35:731-44.

[4] Fan QY, Ma BA, Qiu XC, Li YL, Ye J, Zhou Y. Preliminary report on treatment of bone tumors with microwave-induced hyperthermia. Bioelectromagnetics 1996;17:218-22.

[5] Ikenaga M, Ohura K, Yamamuro T, Kotoura Y, Oka M, Kokubo T. Localized hyperthermic treatment of experimental bone tumors with ferromagnetic ceramics. J Orthop Res 1993;11:849-55.

[6] Charny CK, Guerquin-Kern J, Hagmann MJ, Levin SW, Lack EE, Sindelar WF, Zabell A, Glatstein E, Levin RL. Human leg heating using a mini-annular phased array. Med Phy 1986;13:449-56.

[7] Ogilvie GK, Reynolds HA, Richardson BC, Badger CW, Goss SA, Burdette EC. Performance of a multi-sector ultrasound hyperthermia applicator and control system: in vivo studies. Int J Hyperthermia 1990;6:697-705.

[8] Hynynen K, Shimm D, Anhalt D, Stea B, Sykes H, Cassady JR, Roemer RB. Temperature distributions during clinical scanned, focused ultrasound hyperthermia treatments. Int J Hyperthermia 1990;6:891-908.

[9] Hynynen K, DeYoung D. Temperature elevation at muscle-bone interface during scanned, focused ultrasound hyperthermia. Int $\mathrm{J}$ Hyperthermia 1988;4:267-79.

[10] Corry PM, Barlogie B, Tilchen EJ, Armour EP. Ultrasoundinduced hyperthermia for the treatment of human superficial tumors. Int J Radiat Oncol Biol Phys 1982;8:1225-9.

[11] Fujii M, Sakamoto K, Toda Y, Negishi A, Kanai H. Study of the cause of the temperature rise at the muscle-bone interface during ultrasound hyperthermia. IEEE Trans Biomed Eng 1999;46:494-504.

[12] Hill C. Optimum acoustic frequency for focused ultrasound surgery. Ultrasound Med Biol 1994;20:271-7.

[13] Fry FJ, Dines KA, Reilly CR, Goss SA. Losses in tissue associated with finite amplitude ultrasound transmission. Ultrasound Med Biol 1989;15:481-97.

[14] Carstensen EL, McKay ND, Dalecki D, Muir TG. Absorption of finite amplitude ultrasound in tissues. Acoustica 1982;51:116-23.

[15] Lin WL, Yen JY, Chen YY, Jin KW, Shieh MJ. Relationship between aperture size and tumor conditions for external ultrasound hyperthermia. Med Phy 1999;26:818-24.

[16] Hynynen K. Biophysics and technology of ultrasound hyperthermia. In: Gautherie M, editor. Method of External Hyperthermic Heating. Berlin/Heidelberg/New York: Springer-Verlag, 1990:61-115.

[17] Tu SJ, Hynynen K, Roemer RB. Simulation of bidirectional ultrasound hyperthermia treatments of neck tumours. Int J Hyperthermia 1994;10:707-22.

[18] Moros EG. Simulations of scanned focused ultrasound hyperthermia: The effect of scanning speed, scanning pattern and multiple titled transducers. Master Thesis, Univ. of Arizona, Tucson, Arizona, USA, 1987.

[19] Moros EG, Roemer RB, Hynynen K. Pre-focal plane high temperature regions induced by scanning focus ultrasound beams. Int J Hyperthermia 1990;6:351-66.

[20] Pennes HH. Analysis of tissue and arterial blood temperatures in the resting human forearm. J Appl Physiol 1948;1:93-122.

[21] Chivers RC, Parry RJ. Ultrasonic velocity and attenuation in mammalian tissues. J Acoustic Society Am 1978;63:940-53.

[22] Goss SA, Johnston RL, Dunn F. Comprehensive compilation of empirical ultrasonic properties of mammalian tissues. J Acoustic Society Am 1978;64(2):423-57.

[23] Goss SA, Johnston RL, Dunn F. Comprehensive compilation of 
empirical ultrasonic properties of mammalian tissues, II. J Acoustic Society Am 1982;68(1):93-108.

[24] Hynynen K. Ultrasound heating techonology. In: Seegenschmiedt MH, Feldmann HJ, Vernon CC, editors. Thermoradiotherapy and Thermochemotherapy, vol. 1. Berlin/Heidelberg/New York: Springer-Verlag, 1995:253-79.

[25] Frisch B, Lewis SM, Burkhardt R, Bartl R. Biopsy pathology of bone and bone marrow. London: Chapman and Hall, 1985.

[26] Alves JM, Ryaby JT, Kaufman JJ, Magee PF, Siffert RS. Influence of marrow on ultrasonic velocity and attenuation in bovine trabecular bone. Calcif Tissue Int 1996;58:362-7.

[27] Vertrees RA, Tao W, Pencil SD, Sites JP, Althoff DP, Zwischenberger JB. Induction of whole body hyperthermia with venovenous perfusion. ASAIO J 1996;42:250-4.

[28] McGough R, Ebbini E, Cain C. Direct computation of ultrasound phased-array driving signals from a specified temperature distribution for hyperthermia. IEEE Trans Biomed Eng 1992;39:825-35.
[29] Ebbini E, Cain C. Multiple-focus ultrasound phased-array pattern synthesis: Optimal driving signal distributions for hyperthermia. IEEE Trans Ultrason Ferroelect Freq Contr 1989;36:540-8.

[30] Goss SA, Frizzell LA, Kouzmanoff JT, Barich JM, Yang JM. Sparse random ultrasound phased array for local surgery. IEEE Trans Ultrason Ferroelec Freq Contr 1996;43:1111-21.

[31] Ebbini ES, Cain CA. A spherical-section ultrasound phased array applicator for deep localized hyperthermia. IEEE Trans on Biomed Eng 1991;38:634-43.

[32] Ibbini MS, Ebbini ES, Cain CA. N $\times \mathrm{N}$ square-element ultrasound phased-array applicator simulated temperature distributions associated with directly synthesized heating patterns. IEEE Trans Ultrason Ferroelec Freq Contr 1990;37:491-500.

[33] Fan X, Moros EG, Straube WL. A concentric-ring equivalent phased array method to model fields of large axisymmetric ultrasound transducers. IEEE Trans Ultrason Ferroelec Freq Contr 1999;37:830-41. 